\title{
Penetrating neck trauma: awake tracheostomy, intubation, or both?
}

\author{
John O'Connor, MD, FCAI (iD) Shawn Hicks, MD, MSc, FRCPC
}

Received: 13 May 2020/Revised: 20 May 2020/Accepted: 21 May 2020/Published online: 2 June 2020

(C) Canadian Anesthesiologists' Society 2020

\section{To the Editor,}

Herein we describe the management of a case of penetrating neck injury resulting in a difficult airway due to a knife blade remaining embedded in the trachea. Penetrating neck injury is responsible for approximately $5 \%$ of trauma admissions in North America. ${ }^{1}$ Its reported mortality is approximately $11 \%$, largely due to laceration of the great vessels or airway disruption., ${ }^{2,3}$

There is a lack of evidence regarding the evaluation and management of traumatized airway patients; however, if there are no signs that the airway should be immediately secured, then computed tomography (CT) angiography can be used to determine the extent of the injury. ${ }^{4}$ If the airway must be secured emergently, various techniques including direct laryngoscopy, video laryngoscopy, or flexible bronchoscopy (FB) can be used..$^{5}$

We recently managed a 32-yr-old male (who consented to this report) who presented to the emergency department with a stab wound and knife blade still embedded in his anterior neck. On his primary trauma survey, the peripheral oxygen saturation was $98 \%$ without stridor or subcutaneous emphysema. He was hemodynamically stable, cooperative, but could not lie flat nor extend his neck because of discomfort from the injury. There was no hemoptysis and visible blood loss was minimal. As a cervical spine collar could not be placed because of the protruding blade, manual inline stabilization was maintained at all times until his airway was secured.

A lateral neck radiograph showed the knife blade was embedded approximately $7.5 \mathrm{~cm}$ in the midline of zone 2

J. O'Connor, MD, FCAI $(\bowtie) \cdot$ S. Hicks, MD, MSc, FRCPC

The Ottawa Hospital, Ottawa, ON, Canada

e-mail: jooconnor@toh.ca of his neck (Figure A). He was transferred to the operating room for further management with both an ear, nose, and throat surgeon and a trauma surgeon in attendance. While in the in the seated position, his airway was prepared for FB examination including administering glycopyrrolate (0.3 mg iv), topical lidocaine, plus judicious boluses of fentanyl and midazolam. A Williams airway was well tolerated and oxygen was administered via a nasal cannula. Figure B shows the initial view obtained on FB and showed that the blade was covering $75 \%$ of the proximal subglottic area and minimal view of the true vocal cords.

The anesthetic considerations included potential difficulty in advancing an endotracheal tube (ETT) beyond the blade without damaging the ETT cuff. Given the lack of space around the blade, an airway exchange catheter was also thought to be at risk of causing total airway obstruction. Other options such as a retrograde wire-guided intubation and extra-corporeal membrane oxygenation were also not chosen. An awake tracheostomy was also considered but thought to be difficult because of the blade location and depth as well as the inability of the patient to lie flat and extend his head.

Following a brief multidisciplinary discussion with the surgical team, the patients' neck was marked, prepped, and draped for emergency tracheostomy. Using additional lidocaine topicalization and a remifentanil infusion $\left(0.05 \mu \mathrm{g} \cdot \mathrm{kg}^{-1} \cdot \mathrm{min}^{-1}\right.$ for ten minutes), we advanced an FB loaded with a size 7 ETT and intubated the trachea on the first attempt as the surgeon withdrew the blade. Direct visualization allowed us to avoided advancing the ETT into a false passage. General anesthesia and paralysis then proceeded. Neck exploration revealed a left lateral cricothyroid membrane laceration as well as an anterior laryngeal laceration at the level of the second tracheal ring. A tracheostomy plus detailed bronchoscopy and 


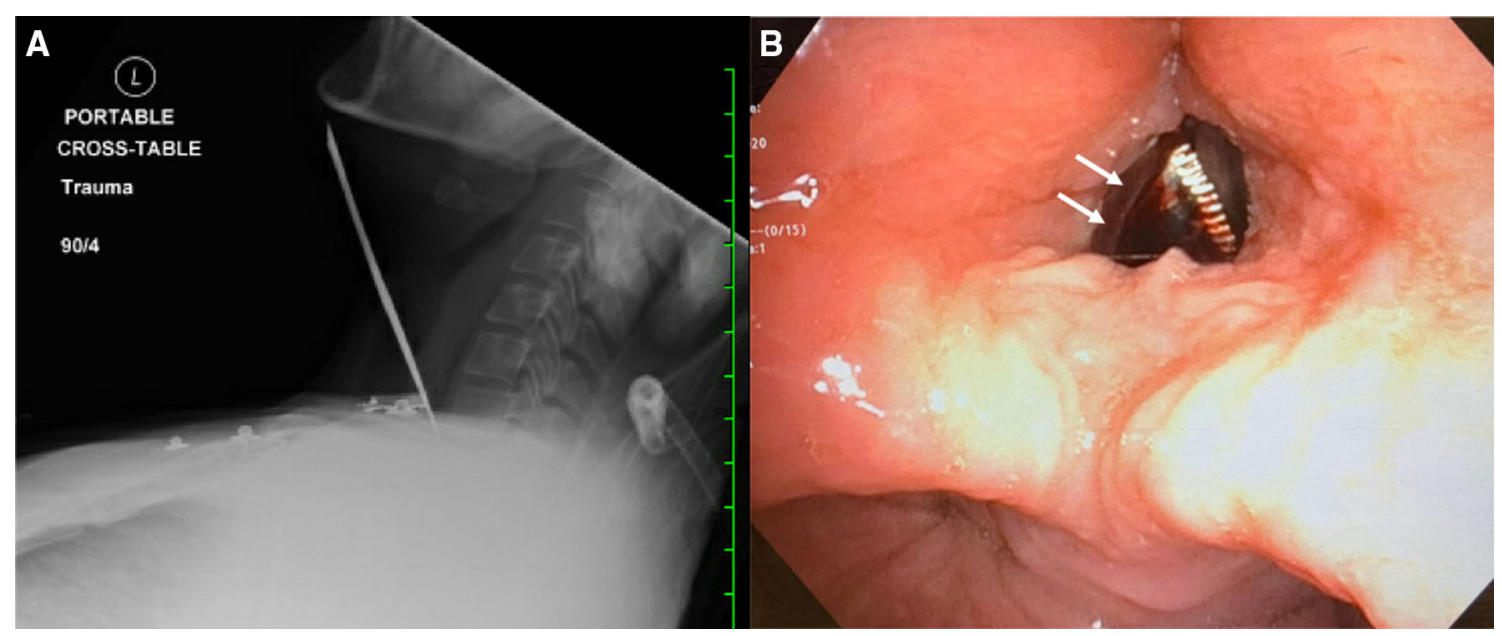

Figure (A) Lateral radiograph of the cervical spine showing a $15-\mathrm{cm}$ blade embedded in the neck. The handle had broken off during the stabbing. There is air deep to the prevertebral soft tissues likely from the airway injury. (B) The supraglottic view using a flexible bronchoscope shows the airway is partially obstructed by the

esophagogastroscopy were carried out uneventfully and the patient was transferred to the intensive care unit after CT angiography of the neck showed no traumatic vascular injury. He was discharged five days later and after tracheostomy decannulation. This case highlights the need for a multidisciplinary approach to secure a traumatized airway, especially when it is partially obstructed.

\section{Disclosures None.}

Funding statement None.

Editorial responsibility This submission was handled by Dr. Hilary P. Grocott, Editor-in-Chief, Canadian Journal of Anesthesia. serrated edge of the blade embedded in the subglottic structures, covering approximately $75 \%$ of the airway. There is mild supraglottic edema, more on the left than the right. The vocal cords are not well visualized but the left true vocal cord is visible to the left of the blade and is discolored because of hematoma (arrows)

\section{References}

1. Nowicki J, Stew B, Ooi E. Penetrating neck injuries: a guide to evaluation and management. Ann R Coll Surg Engl 2018; 100: 611.

2. Kummer C, Netto FS, Rizoli S, Yee D. A review of traumatic airway injuries: potential implications for airway assessment and management. Injury 2007; 38: 27-33.

3. Asensio JA, Valenziano CP, Falcone RE, Grosh JD. Management of penetrating neck injuries: the controversy surrounding zone II injuries. Surg Clin North Am 1991; 71: 267-96.

4. Becker M, Leuchter I, Platon A, Becker CD, Dulguerov P, Varoquaux A. Imaging of laryngeal trauma. Eur J Radiol 2014; 83: $142-54$.

5. Jain U, McCunn M, Smith CE, Pittet JF. Management of the Traumatized airway. Anesthesiology 2016; 124: 199-206.

Publisher's Note Springer Nature remains neutral with regard to jurisdictional claims in published maps and institutional affiliations. 